\title{
Chemoselective Hydrogenation of Alkynes to (Z)-Alkenes using an Air Stable Base Metal Catalyst
}

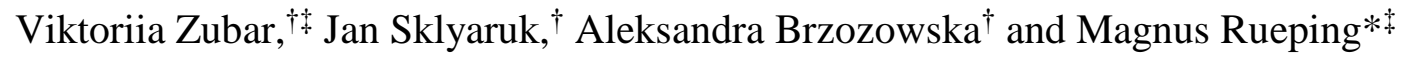 \\ Institute of Organic Chemistry, RWTH Aachen University, Landoltweg 1, 52074, Aachen, Germany \\ \#KAUST Catalysis Center (KCC), KAUST, Thuwal 23955-6900, Saudi Arabia \\ Supporting Information Placeholder
}

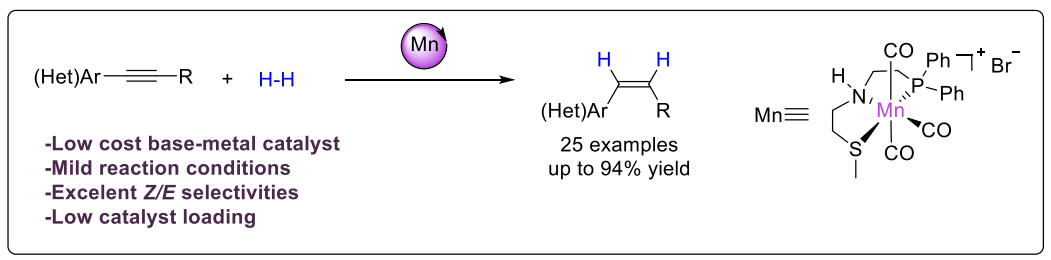

\begin{abstract}
A highly selective hydrogenation of alkynes using an air stable and readily available manganese catalyst has been achieved. The reaction proceeds under mild reaction conditions and tolerates various functional groups resulting in $(Z)$-alkenes and allylic alcohols in high yields. Mechanistic experiments suggest that the reaction proceeds via a bifunctional activation involving metal-ligand cooperativity.
\end{abstract}

The selective semihydrogenation of alkynes to alkenes is a valuable catalytic process. ${ }^{1}$ It is particularly important as it leads to building blocks relevant for the synthesis of pharmaceuticals, agrochemicals and natural products, which encompass a double bond in defined $(E)$ or $(Z)$ configuration. ${ }^{2}$ Different approaches have been developed to prepare $(Z)$-alkenes. ${ }^{3}$ The application of Lindlar`s catalyst is the most popular and widely used hydrogenation to form $(Z)$-alkenes from alkynes. ${ }^{4}$ However, the reaction has disadvantages, such as the toxicity of lead additives or the isomerization of the achieved $(Z)$ to $(E)$-isomer as well as a possible shift of the double bond. Thus, the development of cost-effective, well-defined, efficient and environmentally friendly catalytic systems for the selective conversion of internal alkynes to $(Z)$-alkenes is desirable. However, the semireduction of alkynes to alkenes using hydrogen as a reducing agent is the most efficient and atom economic approach. Concerning homogeneous catalysis most of the known procedures rely on the use of alternative hydrogen donors, such as formic acid, water, silanes, ammonia borane, isopropanol and others. Apart from that, rhodium $^{5}$ and palladium ${ }^{6}$ based catalytic systems showed good reactivity and selectivity towards the formation of (Z)-alkenes with the application of molecular hydrogen as a reducing source. Thus, replacement of the precious metals by the first-row, earth-abundant catalysts would be a valuable alternative procedure. ${ }^{7}$ However, base metal-catalyzed homogeneous hydrogenation of alkynes to $(Z)$-alkenes using hydrogen as reducing agent has hardly been investigated. To the best of our knowledge, the earliest example of a base-metal catalyzed semireduction of alkynes to (Z)-alkenes was reported by Ugo`s group. ${ }^{8 a}$ Phosphine cobalt carbonyl complexes were used for the selective reduction of 2-pentyne resulting in (Z)-2-pentene in good yield. In 2017 Zhang and co-workers ${ }^{8 b}$ successfully applied a cobalt complex formed in-situ from $\mathrm{Co}(\mathrm{OAc})_{2}\left(\mathrm{H}_{2} \mathrm{O}\right)_{4}$,
$\mathrm{NaBH}_{4}$ and ethylenediamine in a 1:2:8 ratio, for the chemoselective hydrogenation of C-C bonds. Iron catalyzed hydrogenation of diphenylacetylene was mentioned in a work of Chirik et al. ${ }^{9}$, where the application of an iron(0) dinitrogen complex initially resulted in the formation of $(Z)$-stilbene which was simultaneously converted to dibenzyl. Furthermore, $\mathrm{Cr}^{10}, \mathrm{~V}^{11}$, and $\mathrm{Cu}^{12}$ salts were also applied.

The availability of manganese as the third most abundant metal in the earth's crust attracted its application in base-metal catalysis. ${ }^{13}$ Recently, we reported the highly selective transfer semihydrogenation of alkynes to (Z)-alkenes using a [Mn(II)$\mathrm{PNP}]\left[\mathrm{Cl}_{2}\right]$ complex and ammonia borane as the hydrogen source. ${ }^{14}$ Due to the fact that ammonia borane is a rather expensive and waste producing reducing agent we decided to evaluate Mn-catalysts which are able to activate molecular hydrogen and to apply them in the reduction of alkynes.

While Mn-catalysts have been applied in hydrogenations before $^{15-19}$ to the best of our knowledge a highly selective manganese catalyzed reduction of alkynes to $(Z)$-alkenes using molecular hydrogen are only recently reported, ${ }^{20}$ although direct hydrogenations are often superior to transfer hydrogenations as they are $100 \%$ atom economic and do not result in by-products. We started our investigation by synthesizing a new, air and moisture stable PhPNS-Mn pincer complex Mn-1 by using a bench stable PhPNS ligand L-1. Mn-1 can be readily synthesized by treatment of $\mathbf{L}-\mathbf{1}$ with 1 equiv. of $\mathrm{Mn}(\mathrm{CO})_{5} \mathrm{Br}$ as metal precursor in toluene at $100{ }^{\circ} \mathrm{C}$ for $16 \mathrm{~h}$. The bright yellow complex was isolated in $86 \%$ yield and was characterized by NMR, IR, and mass spectrometry (Scheme 1). 
Scheme 1. Synthesis of Mn-1.

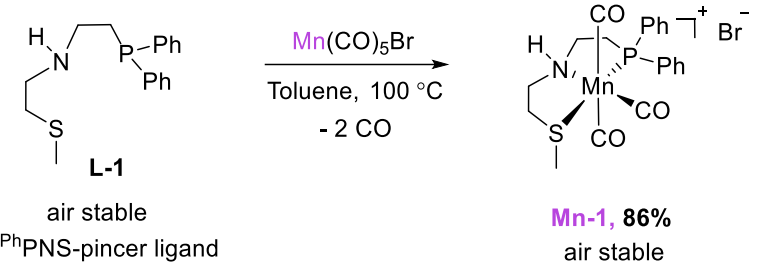

Our newly synthesized catalyst Mn-1 was subsequently investigated in the hydrogenation of diphenylacetylene. Our initial attempts proceeded by applying 1 mol \% of Mn-1 and 2,5 mol $\%$ of $\mathrm{KO}^{t} \mathrm{Bu}$ in toluene at $60^{\circ} \mathrm{C}$ under $30 \mathrm{bar}$ of $\mathrm{H}_{2}$ for $16 \mathrm{~h}$. To our delight, diphenylacetylene was fully consumed producing the desired $(Z)$-stilbene in $88 \%$ GC yield, $1 \%$ of $(E)$-stilbene and $11 \%$ of dibenzyl as a result of over-hydrogenation (Table 1 , entry 1$)$.

The use of manganese complexes, Mn-2, Mn-3 and Mn-4 provided less satisfactory results (Table 1, entries 2-4). To our delight, catalyst Mn-5 showed better reactivity, resulting in $60 \%$ conversion and a selectivity of 98:2 while dibenzyl was not detected (Table 1, entry 5). The application of Mn-6 resulted in lower reactivity albeit similar selectivity when compared to Mn-1 (Table 1, entry 6). A control experiment showed that the reaction does not take place without the catalyst (Table 1, entry 7). Interestingly, the use of $\mathrm{K}_{2} \mathrm{CO}_{3}$ or $\mathrm{Cs}_{2} \mathrm{CO}_{3}$ for the activation of the catalyst was not successful (Table 1 , entries 8 and 9). Use of polar aprotic-THF as a solvent resulted in $11 \%$ conversion of 1a (Table 1, entry 10) while no reaction occurred if polar protic $\mathrm{MeOH}$ was used (Table 1, entry 11). Decreasing the hydrogen pressure to 20 bar helped to reduce the formation of undesired over hydrogenation product (Table 1, entry 12). Performing the reaction at $50{ }^{\circ} \mathrm{C}$ led to the same result (Table 1 , entry 13), nevertheless, $60{ }^{\circ} \mathrm{C}$ appeared to be more suitable for a substrate scope preparation. Additionally, no impact was observed when a drop of mercury was added to the reaction mixture, which suggests the homogeneous nature of the catalyst under these reaction conditions (Table 1 , entry 14$)^{21}$

With the optimized reaction conditions in hand we started to explore the substrate scope for the selective semihydrogenation of alkynes using our new Mn-PNS catalyst. A range of substrates bearing different electronic and steric properties were well tolerated and provided the corresponding $(Z)$-alkenes in good yields with excellent chemoselectivity. It should be noted that the substrates bearing electron withdrawing substituents were significantly more reactive than the ones bearing electron donating groups. Additionally, the hydrogenation of $\mathbf{1 i}$, bearing ester functionality, proceeded chemoselectively towards alkyne hydrogenation and the ester group remained intact. Importantly, alkynes which contain heterocycles (1o-1q, 1x, 1y) could also be applied and provided excellent reactivity and selectivity. Remarkably, no proto-dehalogenation of $\mathrm{C}-\mathrm{Cl}$ and $\mathrm{C}-\mathrm{Br}$ bond took place when 1-chloro-4-(phenylethynyl)benzene (11) and 1bromo-3-(phenylethy-nyl)benzene (1n) were applied as substrates.
Table 1. Optimization of the Reaction Conditions ${ }^{a}$

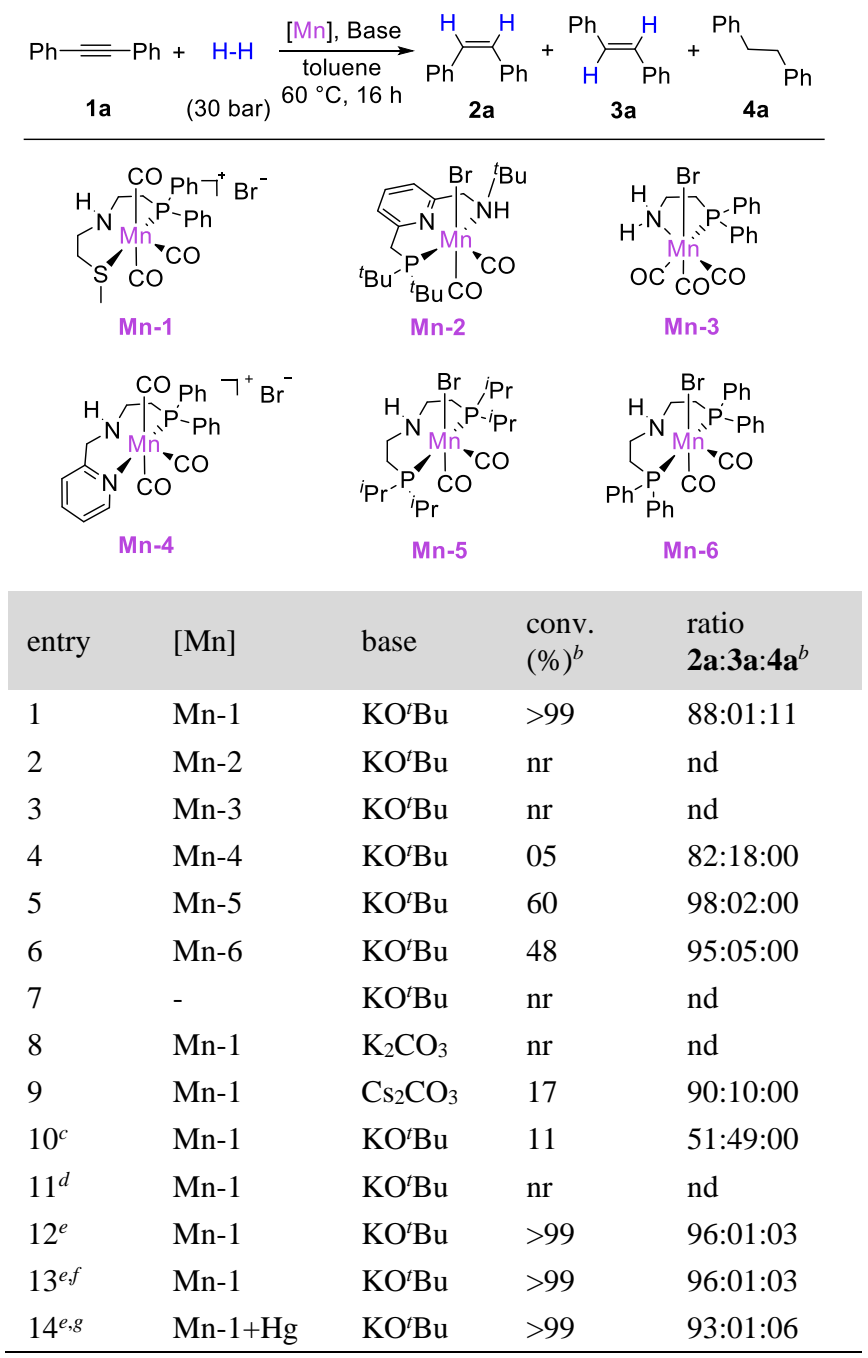

${ }^{a}$ Reaction conditions: 1a $(1 \mathrm{mmol}),[\mathbf{M n}](1 \mathrm{~mol} \%)$, base $(2.5 \mathrm{~mol}$ $\%$ ) in $2 \mathrm{~mL}$ of toluene at $60{ }^{\circ} \mathrm{C}$ under 30 bar of $\mathrm{H}_{2}$ for $16 \mathrm{~h} .{ }^{b}$ Determined by the $\mathrm{GC}$ analysis using $\mathrm{m}$-xylene as internal standard. ${ }^{c} \mathrm{Re}-$ action in THF. ${ }^{d}$ Reaction in methanol. ${ }^{e} 20$ bar of $\mathrm{H}_{2} .{ }^{f} 50{ }^{\circ} \mathrm{C} .{ }^{g}$ One drop of mercury was added.

Moreover, our protocol was suitable for the application of triisopropyl(phenylethynyl)silane $\mathbf{1 r}$ in the hydrogenation reaction. Due to higher steric hindrance of the substrate the reaction required $5 \mathrm{~mol} \%$ of the Mn-1, a slightly higher hydrogen pressure of 30 bar and 24 hours of the reaction time, resulting in $76 \%$ yield of (Z)-triisopropyl-(styryl)silane as a single isomer. Furthermore, the reduction of aryl-alkyl alkynes, including protected propargylic alcohols $\mathbf{1 s - 1 y}$ led to the formation of the corresponding (Z)-allylic alcohols demonstrating the wide scope of substrates. Additionally, a gram-scale synthesis of $(Z)$ stilbene could also be achieved using only $0.5 \mathrm{~mol} \%$ of Mn-1, leading to the formation of $99 \%$ yield of the desired product (Scheme 2) implying that the described protocol could be suitable for industrial production of $(Z)$-alkenes. 
Table 2. (Z)-Selective Hydrogenation of Alkynes Catalyzed by Mn-1 ${ }^{a}$

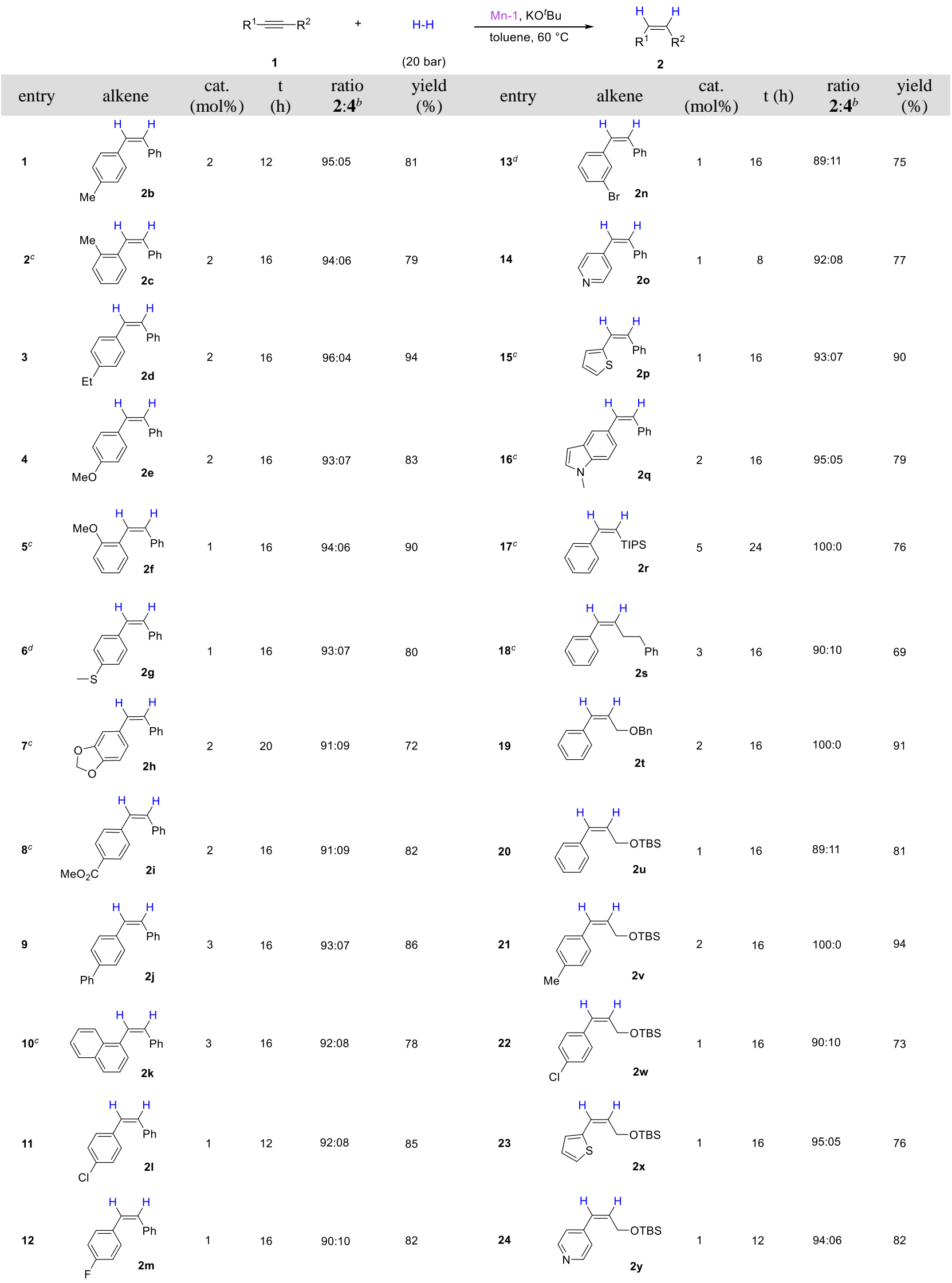

${ }^{a}$ Reaction conditions: alkyne $(0.5 \mathrm{mmol}), \mathbf{M n}-1$ (x mol \%), $\mathrm{KO}^{t} \mathrm{Bu} 2.5$ equiv. to the $\mathrm{Mn}-1$ in $1 \mathrm{~mL}$ of toluene at $60{ }^{\circ} \mathrm{C}$ under 20 bar of $\mathrm{H}_{2}$; yields after purification. ${ }^{b}$ Determined by the NMR analysis using $\mathrm{CH}_{2} \mathrm{Br}_{2}$ as internal standard. ${ }^{c} 30$ bar of $\mathrm{H}_{2} .{ }^{d} 50{ }^{\circ} \mathrm{C}$. 
Scheme 2. Gram-scale Synthesis of (Z)-Stilbene

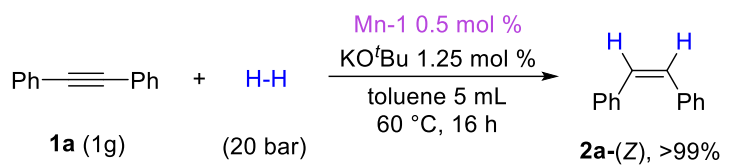

To prove whether the described reaction proceeds via metal-ligand cooperativity we attempted to synthesize the corresponding manganese $\mathbf{N}$-Me derivative of $\mathbf{M n - 1}$ as it would establish whether the proton transfer from the ligand $\mathrm{N}$-atom would occur. As the formation of the Mn-1(N-Me) catalyst was not successful after several attempts, using different solvents and temperatures, we prepared the corresponding $\mathbf{N}-\mathbf{M e}$ manganese complex for Mn-(6), which also showed reactivity in the hydrogenation. As expected, the methylated complex Mn-6(N-Me) appeared to be inactive in the hydrogenation of diphenylacetylene under the optimized reaction conditions, indicating that the formation of the $\mathrm{N}-\mathrm{H}$ is critical for the activity of the catalyst (Scheme 3a). To exclude the possibility of the interaction between the substrate and the catalyst, diphenylacetylene was stoichiometrically added to the Mn-1* (active species), in-situ formed by the addition of $\mathrm{KO}^{t} \mathrm{Bu}$ to the $\mathbf{M n}-\mathbf{1}$ complex and heated for 24 hours in $\mathrm{C}_{6} \mathrm{D}_{6}$ (Scheme $3 \mathrm{~b}$ ). The chemical shift of the activated Mn-1* remained unaffected, indicating that no coordination of the alkyne and potentially inhibition occurs (See SI).

Scheme 3. Mechanistic Studies to Prove Metal-Ligand Cooperativity

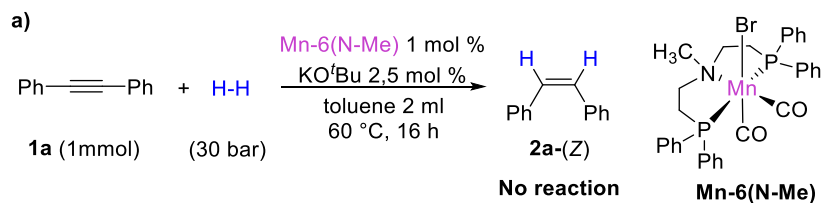

b)

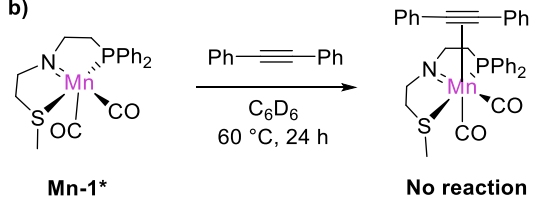

Based on the observed experimental results we propose that the reaction proceeds via metal-ligand cooperativity following an outer-sphere pathway (Scheme 4$){ }^{22}$ Thus, the catalytic cycle begins with the addition of the molecular hydrogen to the metal site of the catalyst and formation of the intermediate $\mathbf{A}$. Next, heterolytic cleavage of the $\mathrm{H}-\mathrm{H}$ bond takes place leading to the hydrogenated catalyst $\mathbf{B}$ via transition state TS-1. A proton and a hydride are transferred simultaneously from the intermediate $\mathbf{B}$ to the substrate giving an intermediate $\mathbf{C}$, which later releases the desired product $\mathbf{2 a}$ and the active catalyst $\mathbf{M n - 1}$.
Scheme 4. Proposed reaction mechanism of alkyne hydrogenation using Mn-1 complex

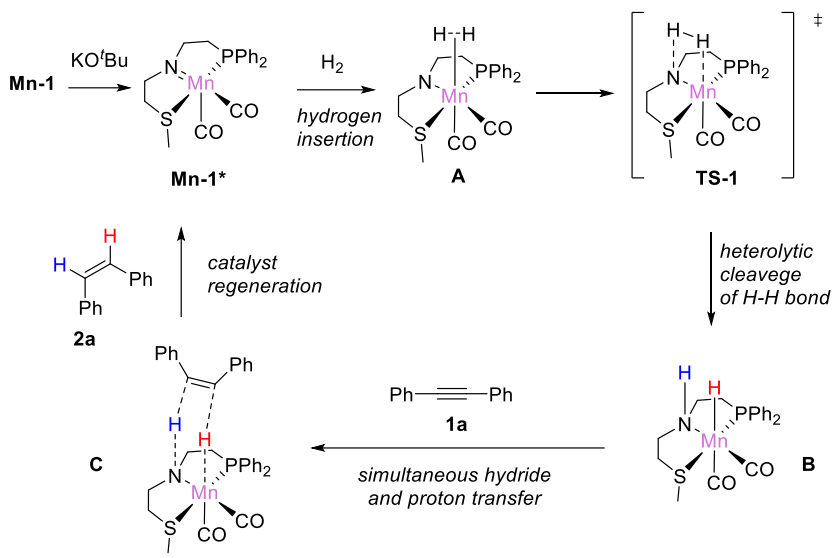

In conclusion, a manganese catalyzed semi-hydrogenation of alkynes using molecular hydrogen as reducing agent has been developed. The reaction proceeds under mild conditions and provides the desired $(Z)$-alkenes with very high selectivity. The applied catalyst Mn-1 can be synthesized from a commercially available manganese precursor and an air stable and readily available ${ }^{\mathrm{Ph}} \mathrm{PNS}$-pincer ligand highlighting the practicability of the developed protocol. The Mn-1 catalyst shows good reactivity and chemoselectivity and tolerates a variety of functional groups and heterocycles leading to a practical synthesis of (Z)olefins as well as allylic alcohols. Compared to transfer hydrogenations with the use of different hydride donors, the use of molecular hydrogen is $100 \%$ atom economic as no by-products are formed. Thus, this mild manganese catalysed reaction provides a good tool to access $(Z)$-alkenes in a stereoselective fashion.

\section{ASSOCIATED CONTENT}

\section{Supporting Information}

The Supporting Information is available free of charge on the ACS Publications website

Experimental data (PDF)

\section{AUTHOR INFORMATION}

\section{Corresponding Author}

*magnus.rueping@kaust.edu.sa

*@rwth-aachen.de

\section{ORCID}

Magnus Rueping: 0000-0003-4580-5227

Notes

The authors declare no competing financial interest

\section{Funding Sources}

J.S. is thankful for a financial support provided by the Fonds der Chemischen Industrie. This work was financially supported by the King Abdullah University of Science and Technology (KAUST), Saudi Arabia, Office of Sponsored Research (FCC/1/1974).

\section{Notes}

Any additional relevant notes should be placed here. 


\section{REFERENCES}

(1) (a) Rylander, P. N. Catalytic Hydrogenation in Organic Syntheses; Academic Press: New York, 1979. (b) De Vries, J. G.; Elsevier, C. J. Handbook of Homogeneous Hydrogenation; Wiley-VCH: Weinheim, Germany, 2007.

(2) Williams, J. M. J. Preparation of Alkenes: A Practical Approach; Oxford University Press: Oxford, U.K. 1996.

(3) (a) Wittig, G.; Schöllkopf, U. Triphenyphosphinemethylene as an olefine-forming reagent; Chem. Ber., 1954, 87, 1318-1330. (b) Horner, L.; Hoffman, H.; Wippel, H.G. Phosphorus organic compounds. XII. Phosphine oxides as reagents for the olefine formation. Chem. Ber, 1958, 91, 61-63. (c) Wadsworth, W. S. Jr.; Emmons, W. D. The utility of phosphonate carbanions in olefin synthesis. J. Am. Chem. Soc. 1961, 83, 1733-1738. (d) Still, W. C.; Gennari, C. Direct synthesis of Z-unsaturated esters. A useful modification of the Horner-Emmons olefination. Tetrahedron Lett. 1983, 24, 4405-4408. (e) Julia, M.; Paris, J.-M., Syntheses with the help of sulfones. V. General method of synthesis of double bonds. Tetrahedron Lett. 1973, 14, 4833-4836. (f) Kocienski, P. J.; Lythgoe, B.; Ruston, S. Scope and stereochemistry of an olefin synthesis from B-hydroxy-sulphones. J. Chem. Soc., Perkin Trans. 1 1978, 829-834. (g) Peterson, D. J. Carbonyl olefination reaction using silyl-substituted organometallic compounds. J. Org. Chem. 1968, 33, 780-784. (h) Fürstner, A. Olefin Metathesis and Beyond. Angew. Chem. Int. Ed. 2000, 39, 3012-3043. (i) Schrock, R. R. High Oxidation State Multiple Metal-Carbon Bonds. Chem. Rev. 2002, 102, 145-180.

(4) (a) Lindlar, H. Ein neuer Katalysator für selektive Hydrierungen. Helv. Chim. Acta, 1952, 35, 446-450. (b) Lindlar, H.; Dubuis, R., Palladium catalyst for partial reduction of acetylenes. Org. Synth. 1966, 46, 89-92.

(5) (a) Osborn, J. A.; Jardine, F. H.; Young, J. F.; Wilkinson, G. The Preparation and Properties of Tris(Triphenylphosphine) Halogenorhodium(I) and Some Reactions Thereof Including Catalytic Homogeneous Hydrogenation of Olefins and Acetylenes and Their Derivatives. Inorg. Phys. Theor. 1966, 1711-1732. (b) Schrock, R. R.; Osborn, J. A. Catalytic Hydrogenation Using Cationic Rhodium Complexes. II. The Selective Hydrogenation of Alkynes to Cis Olefins. J. Am. Chem. Soc.1976, 9, 2143-2147.

(6) (a) Stern, E. W.; Maples, P. K. Homogeneous hydrogenation of unsaturated compounds catalyzed by Pd complexes: II. Deuteriogenation of mono- and diolefins J. Catal. 1972, 27, 134-141. (b) van Laren M.W.; Elsevier C.J. Selective Homogeneous Palladium(0)-Catalyzed Hydrogenation of Alkynes to (Z)-Alkenes. Angew Chem Int Ed. 1999, 38, 3715-3717. (c) Nishibayashi, R.; Kurahashi, T.; Matsubara, S. Palladium Porphyrin Catalyzed Hydrogenation of Alkynes: Stereoselective Synthesis of cis-Alkenes. Synlett 2014; 25, 1287-1290.

(7) Bullock, R. M. Catalysis without Precious Metals, Wiley-VCH Verlag GmbH \& Co. KGaA, Weinheim, Germany, 2010.

(8) (a) Pregaglia, G. F.; Andreetta, A.; Ferrari, G. F.; Ugo, R. Catalysis by Phosphine Cobalt Carbonyl Complexes I. Synthesis and Catalytic Properties of (Tributylphosphine)Cobalt (I) Hydride Carbonyl Complexes. J. Organomet. Chem. 1971, 30, 387-405. (b) Chen, C.; Huang, Y.; Zhang, Z.; Dong, X.-Q.; Zhang, X. Cobalt-Catalyzed (Z)Selective Semihydrogenation of Alkynes with Molecular Hydrogen. Chem. Commun. 2017, 53, 4612-4615. For a study on the alkyne semihydrogenation with a heterobimetallic $\mathrm{Zr} / \mathrm{Co}$ complex, see: (c) Gramigna, K. M.; Dickie, D. A.; Foxman, B. M.; Thomas, C. M. Cooperative $\mathrm{H}_{2}$ Activation across a Metal-Metal Multiple Bond and Hydrogenation Reactions Catalyzed by a Zr/Co Heterobimetallic Complex. ACS Catal. 2019, 9, 3153-3164.

(9) (a) Bart, S. C.; Lobkovsky, E.; Chirik, P. J. Preparation and Molecular and Electronic Structures of Iron(0) Dinitrogen and Silane Complexes and Their Application to Catalytic Hydrogenation and Hydrosilation. J. Am. Chem. Soc. 2004, 126, 13794-13807. For a recent report on Fe-catalyzed semihydrogenation of alkynes, see: (b) Gorgas, N.; Brünig, J.; Stöger, B.; Vanicek, S.; Tilset, M.; Veiros, L. F.; Kirchner, K. Efficient Z-Selective Semihydrogenation of Internal Alkynes Catalyzed by Cationic Iron(II) Hydride Complexes. J. Am. Chem. Soc. 2019, 141, 17452-17458.
(10) Sodeoka, M.; Shibasaki, M. New functions of (arene)tricarbonylchromium $(0)$ complexes as hydrogenation catalysts: stereospecific semihydrogenation of alkynes and highly chemoselective hydrogenation of $\alpha, \beta$.-unsaturated carbonyl compounds. J. Org. Chem. 1985, 50, 1147-1149.

(11) La Pierre, H. S.; Arnold, J.; Toste, F. D. Z-Selective Semihydrogenation of Alkynes Catalyzed by a Cationic Vanadium Bisimido Complex. Angew. Chem., Int. Ed. 2011, 50, 3900-3903.

(12) (a) Semba, K.; Kameyama, R.; Nakao, Y. Copper-Catalyzed Semihydrogenation of Alkynes to Z-Alkenes. Synlett, 2015, 26, 318-322. (b) Pape, F.; Thiel, N. O; Teichert, J. F. Z-Selective Copper(I)-Catalyzed Alkyne Semihydrogenation with Tethered $\mathrm{Cu}$-Alkoxide Complexes. Chem. - Eur. J., 2015, 21, 15934-15938. (c) Wakamatsu, T.; Nagao, K.; Ohmiya, H.; Sawamura, M. Copper-Catalyzed Semihydrogenation of Internal Alkynes with Molecular Hydrogen. Organometallics, 2016, 35, 1354-1357. (d) Thiel, N. O.; Teichert, J. F. Stereoselective alkyne semihydrogenations with an air-stable copper(I) catalyst. Org. Biomol. Chem., 2016, 14, 10660-10666.

(13) For recent reviews on Mn-catalysis, see: (a) Zell, T.; Langer, R. From Ruthenium to Iron and Manganese-A Mechanistic View on Challenges and Design Principles of Base-Metal Hydrogenation Catalysts. ChemCatChem 2018, 10, 1930-1940. (b) Mukherjee, A.; Milstein, D. Homogeneous Catalysis by Cobalt and Manganese Pincer Complexes. ACS Catal. 2018, 8, 11435-11469. (c) Kallmeier, F.; Kempe, R. Manganese Complexes for (De)Hydrogenation Catalysis: A Comparison to Cobalt and Iron Catalysts. Angew. Chem., Int. Ed. 2018, 57, 46-60. (d) Gorgas, N.; Kirchner, K. Isoelectronic Manganese and Iron Hydrogenation/Dehydrogenation Catalysts: Similarities and Divergences. Acc. Chem. Res. 2018, 51, 1558-1569. (e) Filonenko, G. A.; van Putten, R.; Hensen, E. J. M.; Pidko, E. A. Catalytic (de)hydrogenation promoted by non-precious metals - $\mathrm{Co}, \mathrm{Fe}$ and $\mathrm{Mn}$ : recent advances in an emerging field. Chem. Soc. Rev. 2018, 47, 1459-1483. (f) Maji, B.; Barman, M. K. Recent Developments of Manganese Complexes for Catalytic Hydrogenation and Dehydrogenation Reactions. Synthesis 2017, 49, 3377-3393. (g) Garbe, M.; Junge, K.; Beller, M. Homogeneous Catalysis by Manganese-Based Pincer Complexes. Eur. J. Org. Chem. 2017, 4344-4362. (h) Valyaev, D. A.; Lavigne, G.; Lugan, N. Manganese organometallic compounds in homogeneous catalysis: Past, present, and prospects. Coord. Chem. Rev. 2016, 308, 191-235. (i) Carney, J. R.; Dillon, B. R.; Thomas, S. P. Recent Advances of Manganese Catalysis for Organic Synthesis. Eur. J. Org. Chem. 2016, 3912-3929. (j) Liu, W.; Ackermann, L. Manganese-Catalyzed C-H Activation. ACS Catal. 2016, 6, 3743-3752. (k) Wang, C. Manganese-Mediated C-C Bond Formation via C-H Activation: From Stoichiometry to Catalysis. Synlett 2013, 24, 1606-1613. Recent examples from our group: (1) Borghs, J. C.; Zubar, V.; Azofra, L. M.; Sklyaruk, J.; Rueping, M. Manganese Catalyzed Regioselective Dehydrogenative C- vs. N-Alkylation Enabled by a Solvent Switch: Experiment and Computation. Org. Lett. 2020, 22, 4222-4227. (m) Zubar, V.; Borghs, J.; Rueping, M. Hydrogenation or Dehydrogenation of N-Containing Heterocycles Catalyzed by a Single Manganese Complex. Org. Lett. 2020, 22, 3974-3978. (n) Brzozowska, A.; Zubar, V.; Ganardi, R.-C.; Rueping, M. Chemoselective Hydroboration of Propargylic Alkynes using a Manganese(II) catalyst. Org. Lett. 2020, 22, 3765-3769. (o) Borghs, J. C.; Tran, M. A.; Sklyaruk, J.; Rueping, M.; El-Sepelgy, O. Sustainable Alkylation of Nitriles with Alcohols by Manganese Catalysis. J. Org. Chem. 2019, 84, 7927-7935. (p) Borghs, J. C.; Azofra, L. M.; Biberger, T.; Linnenberg, O.; Cavallo, L.; Rueping, M.; El-Sepelgy O. Manganese Catalyzed Multicomponent Synthesis of Pyrroles via Acceptorless Dehydrogenation Hydrogen Autotransfer Catalysis: Experiment and Computation. ChemSusChem 2019, 12, 3083-3088. (q) Matador, E.; Brzozowska, A.; El-Sepelgy, O.; Rueping M. C-Alkylation of Secondary Alcohols with Primary Alcohols through Manganese Catalyzed Double Hydrogen Autotransfer. ChemSusChem 2019, 12, 3099-3102. (r) Borghs, J. C.; Lebedev, Y.; Rueping, M.; El-Sepelgy, O. Sustainable Manganese Catalyzed Solvent-free Synthesis of Pyrroles from 1,4-Diols and Primary Amines. Org. Lett. 2019, 21, 70-74. (s) Jang, Y. K.; Krückel, T.; Rueping, M.; El-Sepelgy, O. Sustainable Alkylation of Unactivated Esters and Amides with Alcohols Enabled by Manganese Catalysis. Org. Lett. 2018, 20, 7779-7783. (t) Wang, C.; Maity, B.; Cavallo, L.; Rueping, M. Manganese catalyzed regioselective $\mathrm{C}-\mathrm{H}$ alkylation of heteroarenes: Experiment and Computation. Org. Lett. 
2018, 20, 3105-3108. (u) Wang, C.; Rueping, M. Rhenium and Manganese-Catalyzed Selective Alkenylation of Indoles. ChemCatChem 2018, 10, 2681-2685

(14) Brzozowska, A.; Azofra, L. M.; Zubar, V.; Atodiresei, I.; Cavallo, L.; Rueping, M.; El-Sepelgy, O. Highly Chemo- and Stereoselective Transfer Semihydrogenation of Alkynes Catalyzed by a Stable, Well-Defined Manganese(II) Complex. ACS Catal., 2018, 8, 41034109.

(15) (a) Elangovan, S.; Topf, C.; Fischer, S.; Jiao, H.; Spannenberg, A.; Baumann, W.; Ludwig, R.; Junge, K.; Beller, M. Selective Catalytic Hydrogenations of Nitriles, Ketones, and Aldehydes by Well-Defined Manganese Pincer Complexes. J. Am. Chem. Soc. 2016, 138, 88098814. (b) Glatz, M.; Stöger, B.; Himmelbauer, D.; Veiros, L. F.; Kirchner, K. Chemoselective Hydrogenation of Aldehydes under Mild, Base-Free Conditions: Manganese Outperforms Rhenium. ACS Catal. 2018, 8, 4009-4016.

(16) (a) Kallmeier, F.; Irrgang, T.; Dietel, T.; Kempe, R. Highly Active and Selective Manganese $\mathrm{C}=\mathrm{O}$ Bond Hydrogenation Catalysts: The Importance of the Multidentate Ligand, the Ancillary Ligands, and the Oxidation State. Angew. Chem., Int. Ed. 2016, 55, 11806-11809. (b) Perez, M.; Elangovan, S.; Spannenberg, A.; Junge, K.; Beller, M. Molecularly Defined Manganese Pincer Complexes for Selective Transfer Hydrogenation of Ketones. ChemSusChem. 2017, 10, 83-86. (c) Bruneau-Voisine, A.; Wang, D.; Roisnel, T.; Darcel, C.; Sortais, J.$\mathrm{P}$. Hydrogenation of ketones with a manganese $\mathrm{PN}^{3} \mathrm{P}$ pincer pre-catalyst. Catal. Commun. 2017, 92, 1-4. (d) Bruneau-Voisine, A.; Wang, D.; Dorcet, V.; Roisnel, T.; Darcel, C.; Sortais, J.-B. Transfer Hydrogenation of Carbonyl Derivatives Catalyzed by an Inexpensive Phosphine-Free Manganese Precatalyst. Org. Lett. 2017, 19, 3656-3659. (e) Zirakzadeh, A.; de Aguiar, S. R. M. M.; Stöger, B.; Widhalm, M.; Kirchner, K. Enantioselective Transfer Hydrogenation of Ketones Catalyzed by a Manganese Complex Containing an Unsymmetrical Chiral PNP' Tridentate Ligand. ChemCatChem. 2017, 9, 1744-1748. (f) Widegren, M. B.; Harkness, G. J.; Slawin, A. M. Z.; Cordes, D. B.; Clarke, M. L. A Highly Active Manganese Catalyst for Enantioselective Ketone and Ester Hydrogenation. Angew. Chem., Int. Ed. 2017, 56, 58255828.

(17) (a) Elangovan, S.; Garbe, M.; Jiao, H.; Spannenberg, A.; Junge, K.; Beller, M. Hydrogenation of Esters to Alcohols Catalyzed by Defined Manganese Pincer Complexes. Angew. Chem., Int. Ed. 2016, 55, 15364-15368. (b) Espinosa-Jalapa, N. A.; Nerush, A.; Shimon, L. J.
W.; Leitus, G.; Avram, L.; Ben-David, Y.; Milstein, D. ManganeseCatalyzed Hydrogenation of Esters to Alcohols. Chem. - Eur. J. 2017, 23, 5934-5938. (c) van Putten, R.; Uslamin, E. A.; Garbe, M.; Liu, C.; Gonzalez-de-Castro, A.; Lutz, M.; Junge, K.; Hensen, E. J. M.; Beller, M.; Lefort, L.; Pidko, E. A. Non-Pincer-Type Manganese Complexes as Efficient Catalysts for the Hydrogenation of Esters. Angew. Chem. Int. Ed. 2017, 56, 7531-7534.

(18) Papa, V.; Cabrero-Antonio, J. R.; Alberico, E.; Spanneberg, A.; Junge, K.; Junge, H.; Beller, M. Efficient and selective hydrogenation of amides to alcohols and amines using a well-defined manganesePNN pincer complex. Chem. Sci. 2017, 8, 3576-3585.

(19) (a) Kumar, A.; Janes, T.; Espinosa-Jalapa, N. A.; Milstein, D. Manganese Catalyzed Hydrogenation of Organic Carbonates to Methanol and Alcohols. Angew. Chem. Int. Ed. 2018, 57, 12076-12080. (b) Zubar, V.; Lebedev, Y.; Azofra, L. M.; Cavallo, L.; El-Sepelgy, O.; Rueping, M. Hydrogenation of $\mathrm{CO}_{2}$-Derived Carbonates and Polycarbonates to Methanol and Diols by Metal-Ligand Cooperative Manganese Catalysis. Angew. Chem. Int. Ed. 2018, 57, 13439-13443. (c) Kaithal, A.; Hölscher, M.; Leitner, W. Catalytic Hydrogenation of Cyclic Carbonates using Manganese Complexes Angew. Chem. Int. Ed. 2018, 57, 13449-13453.

(20) During the submission of this manuscript a report on Mn-catalyzed semihydrogenation of alkynes appeared: Garbe, M; Budweg, S.; Papa, V.; Wei, Z.; Hornke, H.; Bachmann, S.; Scalone, M.; Spannenberg, A.; Jiao, H.; Junge, K.; Beller, M. Chemoselective semihydrogenation of alkynes catalyzed by manganese(I)-PNP pincer complexes. Catal. Sci. Technol., 2020, DOI: 10.1039/d0cy00992j.

(21) Chernyshev, V. M.; Astakhov, A. V.; Chikunov, I. E.; Tyurin, R. V.; Eremin, D. B.; Ranny, G. S.; Khrustalev, V. N.; Ananikov V. P. $\mathrm{Pd}$ and Pt Catalyst Poisoning in the Study of Reaction Mechanisms: What Does the Mercury Test Mean for Catalysis? ACS Catal. 2019, 9, 2984-2995.

(22) For reviews on metal-ligand cooperative catalysis and pincer complexes, see: (a) Khusnutdinova, R.; Milstein, D. Metal-Ligand Cooperation. Angew. Chem., Int. Ed. 2015, 54, 12236-12273. (b) Luca, O. R.; Crabtree, R. H. Redox-active ligands in catalysis. Chem. Soc. Rev. 2013, 42, 1440-1459. (c) Lyaskovskyy, V.; de Bruin, B. Redox NonInnocent Ligands: Versatile New Tools to Control Catalytic Reactions. ACS Catal. 2012, 2, 270-279. (d) H. Li, T. P. Gonçalves, D. Lupp, K.W. Huang, PN3(P)-Pincer Complexes: Cooperative Catalysis and Beyond. ACS Catal. 2019, 9, 1619-1629. 